\title{
Environmental Conflicts in the Mirror of the «Civilization of Maximization»
}

\author{
Sergey N. Bobylev*, Sofya V. Solovyeva \\ and Irina Yu. Khovavko \\ Lomonosov Moscow State University \\ Moscow, Russian Federation
}

Received 24.05.2021, received in revised form 15.06.2021, accepted 29.06.2021

\begin{abstract}
The type of civilization formed on the planet can be defined as a «civilization of maximization», which is focused on the growth of financial results, production of goods and services, and consumption. This type of civilization leads to numerous environmental conflicts at all levels. In this regard, it seems promising to study the mechanisms of internalization of externalities as a basis for preventing and overcoming environmental conflicts. The types of environmental conflicts are identified, depending on the scope of the covered impact and the externalities that generate them: temporal, global, intercountry, intersectoral, interregional and local. The article analyzes the problem of climate change as a significant example of an environmental conflict caused by the temporal and global externalities of the «civilization of maximization». Large corporations, being the drivers of the "civilization of maximization,» at the same time increasingly participate in the environmental transformation of the world and national economies.
\end{abstract}

Keywords: environmental conflicts, externalities, climate change, carbon neutrality, corporate social responsibility, ecological transformation of the world economy.

The reported study was funded by the Russian Federal Property Fund according to the research project No. 20-010-00981\20«Formation of a circular economy and resolution of environmental conflicts».

Research area: economics.

Citation: Bobylev, S.N., Solovyeva, S.V., Khovavko, I. Yu. (2021). Environmental conflicts in the mirror of the «civilization of maximization». J. Sib. Fed. Univ. Humanit. Soc. Sci., 14(7), 956-965. DOI: $10.17516 / 1997-1370-0775$.

\footnotetext{
(C) Siberian Federal University. All rights reserved

* Corresponding author E-mail address: snbobylev@yandex.ru, solovyevasv@gmail.com, irina.hov@rambler.ru ORCID: 0000-0001-5269-9026 (Bobylev); 0000-0002-2471-8434 (Solovyeva); 0000-0003-3273-0414 (Khovavko)
} 


\title{
Экологические конфликты в зеркале «цивилизации максимизации»
}

\author{
С.Н.Бобылев, С.В. Соловьева, И.Ю. Ховавко \\ Московский государственный университет имени М. В. Ломоносова \\ Российская Федерация, Москва
}

\begin{abstract}
Аннотация. Сформировавшийся на планете тип цивилизации можно определить как «цивилизация максимизации», который ориентирован на рост финансовых результатов, производство товаров и услуг, потребление. Такой цивилизационный тип порождает многочисленные экологические конфликты на всех уровнях. В связи с этим представляется перспективным исследование механизмов интернализации экстерналий как основы для предупреждения и разрешения экологических конфликтов. В зависимости от сферы охватываемого воздействия выделены типы экологических конфликтов, зависящих от порождающих их экстерналий: темпоральные, глобальные, межстрановые, межсекторальные, межрегиональные и локальные. В статье анализируется проблема изменения климата как актуальный пример экологического конфликта, вызванного темпоральными и глобальными экстерналиями и характерного для «цивилизации максимизации». В настоящее время крупнейшие корпорации и банки мира все активнее участвуют в экологической трансформации мировой и национальных экономик, процессах низкоуглеродного развития, чему способствует включение в их деятельность нефинансовых экологических и социальных факторов, корпоративной социальной ответственности, ESG-критериев.
\end{abstract}

Ключевые слова: экологические конфликты, внешние эффекты, изменение климата, углеродная нейтральность, корпоративная социальная ответственность, экологическая трансформация мировой экономики.

Исследование выполнено при финансовой поддержке РФФИ в рамках научного проекта № 20-010-00981 \20 «Формирование циркулярной экономики и разрешение экологических конфликтов».

Научная специальность: 08.00.00 - экономические науки.

\section{Введение}

В экономической истории человечества 2020 г. стал определенным рубежом не только из-за пандемии COVID-19, но и из-за принятых решений по радикальному изменению экономической модели развития человечества. Подавляющая часть мировой экономики в качестве цели развития выдвинула достижение углеродной нейтральности, экологической устойчивости к 2050-2060 гг. Среди стран, принявших такое решение, можно отметить членов Европейского сообщества, Китай, США, Японию, Южную Корею. Таким образом, рост благосостояния населения, повышение доходов, борьба с безработицей и неравенством и другие приоритетные социальноэкономические проблемы должны решаться в жестких рамках экологических лимитов и ограничений.

Такая достаточно радикальная смена курса интенсивно готовилась последние десять лет. Здесь можно упомянуть фундаментальные решения трех конференций $\mathrm{OOH}$ : Рио-де-Жанейро 2012 «Будущее, которое мы хотим» (UN, 2012), Нью-Йорк («Повестка дня в области устойчивого развития на период до 2030 года») (UN General Assembly..., 2015), Париж (Парижское климатическое соглашение) (UN, 2015). 
В чем причина такой радикальной смены курса глобальной экономики? На наш взгляд, это осознание «тупиковости» сложившейся модели развития, которая выходит за экологические пределы существования человечества, рамки экологической емкости. За последние четверть века наблюдался огромный рост мировой экономики, увеличение мирового ВВП составило почти 5 раз, что позволило повысить материальное благосостояние сотен миллионов людей. Однако на этом фоне выявились экологические ограничения, связанные со сложившимися моделями производства и потребления. В частности, для достижения в мире стандартов потребления среднего американца требуется пять таких планет, как Земля.

Необходимо радикальное изменение сложившейся парадигмы развития, «переформатирование» всей деятельности человечества в соответствии с парадигмой устойчивого развития во всем ее многообразии и сбалансированности социальных, экономических и экологических факторов. Человечество сформировало такой тип цивилизации, который можно охарактеризовать как «цивилизация максимизации» (Bobylev, 2019). Такая цивилизация максимизирует три цели: финансовые результаты, производство, потребление. Становится все более очевидно, что «цивилизация максимизации» не может быть устойчивой и необходимо менять достаточно глубинные и утвердившиеся цивилизационные приоритеты. В связи с этим нужно отметить важность достижения 12-й Цели устойчивого развития ООН, связанной с радикальным изменением моделей производства и потребления.

«Сверхпроблемой» перехода к устойчивому развитию является трансформация устоявшихся основ «цивилизации максимизации» в виде традиционного рынка. Во многих международных документах, в высказываниях ученых отмечена необходимость формирования новой философии развития. Даже на Всемирном экономическом форуме в Давосе в 2020 г., объединяющем респектабельные мировые политические, деловые и научные элиты, предлагалась новая модель «капитализма всех заинтересованных сторон» (stakeholder capitalism) (World Economic Forum, 2020). В этой модели цель компании должна состоять в вовлечении заинтересованных сторон в «устойчивое создание ценности». В последнем докладе 2021 г. Всемирного экономического форума четыре из пяти глобальных рисков для человечества были экологическими (World Economic Forum, 2021).

Противоречия в обществе, обусловленные экологическими факторами, ведут к многообразным конфликтам между человеком и биосферой, между сообществами на всех пространственных уровнях, возникает этическая проблема ответственности перед будущими поколениями. Опыт регулирования конфликтных ситуаций в экологической сфере является важным элементом современных технологий управления. Основное внимание в статье уделено исследованию и идентификации экологических конфликтов, их связи с экстерналиями в рамках сформировавшейся «цивилизации максимизации». Особый акцент сделан на изучении темпоральных и глобальных конфликтов на примере проблемы изменения климата.

\section{Идентификация \\ и классификация \\ экологических конфликтов}

В настоящее время в мире не сложилось последовательной и логичной теории экологических конфликтов, тем не менее в этой области работают много специалистов из различных научных отраслей. В целом в западной литературе существует достаточно узкая трактовка понятия «экологический конфликт». С начала 1990-х гг. прошлого века внимание западной научной общественности обратилось к так называемым экологически обусловленным конфликтам (environmentally induced conflicts). Изучение экологических конфликтов («environmental conflicts», «ecological conflicts») ведется на стыке политической экологии (political ecology), экологической 
экономики или экономики природопользования (ecological economics), промышленной экологии (industrial ecology) и наук, занимающихся проблемами национальной безопасности. Учитывая этот факт, отметим отсутствие единого языка для описания таких понятий, как «экологический конфликт», «конфликт природопользования», «природоресурсный конфликт». Иногда под экологическими конфликтами понимают любые «ресурсные войны» (Le Billon, 2012), в качестве причин возникновения которых рассматриваются три вида дефицита ресурсов (дефицит из-за повышенного спроса, дефицит из-за сокращения предложения и структурный дефицит, вызванный несправедливым распределением имеющихся ресурсов) (Homer Dixon, 1994). Более распространена точка зрения, согласно которой к экологическим относятся конфликты, связанные с экологической деградацией, понимаемой более узко (деградация возобновляемых природных ресурсы и ассимиляционного потенциала). Эта точка зрения развивается в работах Джоана Матинез-Алиера (Martinez-Alier, 2010, 2007, 2004), Шломи Динара (Shlomi, 2011), Стефана Либишевски (Libiszewski, 1992), Курта Шпильмана (Mason, Spillmann, 2005) и др.

В качестве ведущих подходов к способам разрешения/предотвращения конфликтов рассматриваются два: экономическая оценка ущербов и возможная их компенсация или защита прав человека на благоприятную окружающую среду и/или прав коренных народов (Scheidel et al., 2020).

Отечественная конфликтология активно развивается в последние десятилетия, вместе с тем комплексных исследований явно недостаточно. Выпущен ряд работ российских авторов, а также переводных изданий, посвященных политическим, социальным, психологическим, юридическим аспектам управления конфликтами. Обычно экологические конфликты рассматриваются в отечественной литературе как системные конфликты, предметом которых выступают притязания на определенный природный ресурс, способы его использования, права собственности, контроль над ним и т. д. (Mylina, 2014, Sabadash, 2010). Попытки классификации экологических конфликтов по целому ряду параметров предприняты в работах М.В. Терешиной (Tereshina, 2009) и А. Л. Демчука (Demchuk, 2020). На экономическую природу экологических конфликтов обращено внимание в работах И.Ю. Ховавко (Khovavko, 2016), где показано, что в основе экологических конфликтов лежат экономические причины, связанные с распределением издержек от негативных экологических экстерналий.

В данной статье авторы предлагают в зависимости от сферы охватываемого воздействия выделять следующие шесть типов экологических конфликтов, зависящих от порождающих их экстерналий: темпоральные, глобальные, межстрановые, межсекторальные, межрегиональные и локальные:

Темпоральные (временные, межпоколенческие) конфликты. Здесь принципиальным экономическим моментом является возложение дополнительных экстернальных затрат современным поколением на будущие поколения. Традиционное понимание экономического компромисса поколений во многом определяется соотношением их моделей потребления и накопления: «каждое поколение должно сберегать для будущих поколений такую же часть национального дохода, какую оставило ему предыдущее поколение». Современный взгляд расширяет этот принцип на природу - «каждое поколение должно оставить планету в не худшем состоянии, чем оно ее получило» (Barry, 1999).

Глобальные конфликты. Данный вид конфликтов связан с экологическими проблемами глобального масштаба (трансграничное загрязнение, загрязнение Мирового океана, вырубка тропических лесов и др.).

Межстрановые конфликты. Здесь типичным примером являются водные проблемы, связанные с развитием орошаемого сельского хозяйства, гидроэнергетикой и т. д. Сейчас самые многочисленные в мире конфликты связаны с использованием водных ресурсов. Примеры таких конфликтов имеются в Африке, Латинской 
Америке, Ближнем Востоке, Центральной Азии.

Межсекторальные конфликты. Развитие природоэксплуатирующих секторов экономики наносит значительный ущерб, то есть вызывает отрицательные внешние эффекты, другим секторам. Например, аграрный сектор несет большие потери в результате добычи полезных ископаемых.

Межрегиональные конфликты. Этот вид конфликтов является уменьшенной копией глобальных экстерналий, только в рамках одной страны. Классическим примером могут быть реки, когда находящиеся в верхнем течении регионы своими загрязнениями создают дополнительные затраты на очистку воды у «нижних» регионов.

Локальные конфликты. Самый распространенный и изученный тип конфликтов, связанный с локальными экстерналиями: объект - источник экстерналий и локальная территория, на которой внешние издержки возлагаются на местное сообщество.

Для купирования экологических конфликтов и интернализации экстерналий на разных уровнях применяется широкий спектр инструментов, включающий в себя: методы прямого государственного регулирования (нормативы, стандарты); экономические рыночные инструменты (налоги, плата за пользование, системы квотирования и торговли разрешениями); институциональные инструменты (прозрачность отчетности и информации, включение экологического фактора в добровольные инициативы бизнеса и др.).

\section{Темпоральные и глобальные} экологические конфликты: что делать?

На сегодняшний день разработаны инструменты экологического регулирования, позволяющие интернализировать негативные экстерналии разных уровней. Однако результат (повышение эффективности аллокации ресурсов) существенным образом зависит от того, кто и для каких целей использует эти инструменты. Особенно это относится к механизмам регулирования темпоральных и глобальных экологических экстерналий.
Рассмотрим проблему изменения климата как пример экологического конфликта, вызванного темпоральными и глобальными экстерналиями и характерного для «цивилизации максимизации». Происходящая на наших глазах гигантская трансформация преобладающей части мировой экономики, нацеленная на достижение углеродной нейтральности к 2050-2060 гг., направлена на решение климатической проблемы. При сохранении традиционной траектории развития мировой экономики (business as usual), по имеющимся оценкам, температура Земли может возрасти на 3-4 градуса, что приведет к огромным экономическим потерям. У России две трети территории находится в зоне вечной мерзлоты, и, по оценкам Росгидромета, рост температуры в северных регионах в среднем в 4 раза превышает темпы глобального потепления, что также может привести к значительным экономическим и социальным потерям.

Налицо конфликт между современными поколениями, создавшими неустойчивую «коричневую» экономику с высокими выбросами парниковых газов и деградирующими климатическую систему, и следующими поколениями, которые должны нести огромные дополнительные издержки для стабилизации социально-экономической ситуации и ликвидации отдаленных последствий современных экологических ущербов. В области климатических изменений главными «виновниками» создавшейся ситуации являются Китай, США, Индия и Россия, на долю которых приходится свыше половины всех мировых выбросов парниковых газов.

Несмотря на продолжающиеся дискуссии о причинах и тенденциях климатических изменений, мировая экономика признала их реальность и важнейшую роль антропогенного фактора. Это признание выразилось в сотнях миллиардах долларов, евро, юаней, направленных на борьбу с изменением климата посредством создания новых низкоуглеродных технологий, экономических структур, экономических механизмов регулирования, законов и со- 
глашений, дивестиций и перераспределения инвестиций. То есть именно гипотеза об однозначной антропогенной обусловленности происходящих климатических изменений позволяет рассматривать климат как разновидность глобальных экологических экстерналий (и, соответственно, конфликтов).

Для стабилизации климатической системы и для объединения усилий всех стран в 1992 г. была принята Рамочная конвенция ООН об изменении климата, для реализации которой были приняты Киотский протокол (1997) и Парижское климатическое соглашение (2015). Киотский протокол дал конструктивный опыт мировой экономике, показывающий, что можно регулировать/уменьшать выбросы парниковых газов и при этом не снижать экономические результаты развития и рост благосостояния. В основе реализации климатической политики в мире лежат разнообразные рыночные инструменты, в том числе базирующиеся на «углеродной» цене, формирующейся на основе торговли квотами парниковых газов или углеродных налогов.

Несмотря на предпринимаемые усилия по борьбе с климатическими изменениями, в мире не удается преодолеть инерционные тенденции развития экономики, особенно в развивающихся странах, что приводит к дальнейшему росту глобальной температуры и вероятным превышениям лимитов Парижского соглашения в 21 в. $\left(1,5-2{ }^{\circ} \mathrm{C}\right)$.

Для борьбы с климатическими угрозами Россия за последние годы активизировала свою климатическую активность на международной арене и внутри страны. В 2009 г. в России была принята Климатическая доктрина, подписано и ратифицировано Парижское климатическое соглашение (2019), подготовлены проекты Стратегии социально-экономического развития Российской Федерации с низким уровнем выбросов парниковых газов до 2050 г. (2020) и Закона об углеродном регулировании (2020). Однако механизмы реализации последних двух документов проработаны недостаточно.

\section{Изменение роли корпораций}

Одним из мощных драйверов развития «цивилизации максимизации» являются корпорации. Их традиционные цели, связанные с ориентацией на финансовые результаты, рост прибыли фактически стимулируют неустойчивые модели производства и потребления. По оценкам Всемирного совета бизнеса за устойчивое развитие, на долю 3000 крупнейших мировых компаний приходится треть глобального экологического ущерба (The World Business..., 2011). Такие ущербы способствуют развитию экологических конфликтов на всех уровнях от темпорального до локального. Огромны экологические экстерналии от деятельности корпораций, их интернализация зачастую требует огромных средств. Например, в результате аварии нефтяной платформы ВР в Мексиканском заливе (2010) компания выплатила около 60 млрд долл. Это был острый межсекторальный и межрегиональный конфликт, когда из-за данной катастрофы пострадали секторы туризма, рыболовства, водоснабжения и др., а также люди и животный мир в пяти юго-восточных штатах США. В России авария с разливом нефтепродуктов на предприятии «Норникеля» (2020) в Красноярском крае привела к выплате корпорацией гигантской суммы в 146 млрд руб. штрафа на основе иска Росприроднадзора.

Важная особенность современного этапа развития - попытки корпораций изменить модели производства и потребления в обществе. Для этого компании все более широко включают в свою деятельность принципы, заложенные в Целях устойчивого развития ООН (2016-2030) и Парижском соглашении по климату (2015). Учет обязательств перед обществом и сохранение природы, этические проблемы становятся существенными факторами, способствующими улучшению экономических показателей, усиливающих конкурентные позиции в странах и на глобальном уровне. В качестве механизмов реализации социоэкологических приоритетов в деятельности корпораций чаще всего выступают корпоративная социальная ответственность, раз- 
личного вида отчеты (нефинансовые, социальные, в области устойчивого развития, экологические), устойчивое и ответственное инвестирование, «зеленое» финансирование и т. д.

Позитивный имидж крупной компании уже невозможен без широко распространенной в мире корпоративной социальной ответственности (КСО), предусматривающей интеграцию интересов общества и окружающей среды в свои бизнес-процессы и свои взаимодействия с заинтересованными сторонами (стейкхолдерами) на добровольных началах. Тем самым компании принимают на себя ответственность за влияние их деятельности и принимаемых решений на общество и природу, смягчение и предотвращение экологических конфликтов. При рассмотрении вопросов внедрения КСО часто используются критерии и аббревиатура ESG (E - окружающая среда (Environment), $\mathrm{S}$ - общество (Social), G - корпоративное управление (Governance)). Эти критерии уже применяются крупнейшими международными и российскими корпорациями. Для поддержки экологизации экономики в 2006 г. были сформулированы «Принципы ответственного инвестирования $\mathrm{OOH}$ (Principles for Responsible Investment Initiative). К 2020 г. к этим принципам присоединились 2300 финансовых институтов, а общая сумма их активов составила 80 трлн долл. (UN Principles for Responcible Investment, 2020). Также нефинансовая информация часто предоставляется на основе Глобальной инициативы по отчетности (Global Reporting Initiatives).

Особенно четко экологическая трансформация целей корпораций проявляется в области низкоуглеродных тенденций, перехода к углеродной нейтральности, связанных с борьбой с изменением климата и смягчением глобальных и темпоральных конфликтов. В странах ЕС банки начали оценивать воздействие рисков, связанных с изменением климата и переходом к низкоуглеродной экономике в финансовом секторе. Наш анализ деятельности крупнейших банков Германии, Швейцарии, Великобритании, США (Credit Suisse,
Deutsche Bank, Citigroup, Barclays, UBS и др.) показал, что в программах их развития акцент делается на резкое увеличение финансирования «зеленых» проектов, ориентацию на устойчивое и низкоуглеродное развитие, уход из угольных проектов, отказ от поддержки промышленной деятельности в Арктике. Последние два направления, связанные с фактическим прекращением поддержки добычи угля и свертыванием промышленных проектов в Арктике, представляют для России определенные проблемы как в концептуальном, так и в практическом плане.

Еще более парадоксальные цели с точки зрения традиционного экономического развития заявили крупнейшие международные нефтегазовые компании, генерирующие огромные экологические ущербы и острые конфликты. Так, в 2020 г. компания ВР заявила о реализации стратегии «чистого нуля» (net zero), которая предполагает достижение нулевого углеродного баланса к 2050 г. О стремлении к низкоуглеродному развитию и резком сокращении выбросов парниковых газов к 2050 г. объявили Eni, Shell, Repsol, Total и др. В России Лукойл заявил об ориентации в своей деятельности на достижение углеродной нейтральности к 2050 г.

\section{Заключение}

Сформировавшийся на планете тип цивилизации можно определить как «цивилизация максимизации», он ориентирован на рост финансовых результатов, производство товаров и услуг, потребление. Такой цивилизационный тип порождает многочисленные экологические конфликты на всех уровнях. Представляется перспективным исследование механизмов интернализации экстерналий как основы для предупреждения и разрешения экологических конфликтов. В зависимости от сферы охватываемого воздействия можно выделить типы экологических конфликтов, зависящих от порождающих их экстерналий: темпоральные, глобальные, межстрановые, межсекторальные, межрегиональные и локальные. 
Проблема изменения климата является ярким и актуальным примером экологического конфликта, вызванного темпоральными и глобальными экстерналиями и характерного для «цивилизации максимизации». Происходящая гигантская трансформация преобладающей части мировой экономики, нацеленная на достижение углеродной нейтральности к 2050-2060 гг., направлена на решение климатической проблемы. Налицо конфликт между современными поколениями, создавшими неустойчивую «коричневую» экономику с высокими выбросами парниковых газов и деградирующую климатическую систему, и следующими поколениями, которые должны нести огромные дополнительные издержки для стабилизации социально-экономической ситуации и ликвидации отдаленных последствий современных экологических ущербов.

Крупнейшие корпорации и банки мира принимают участие в обострении проблемы экологических конфликтов на всех уровнях. В настоящее время крупный бизнес все активнее участвует в экологической трансформации мировой и национальной экономик, процессах низкоуглеродного развития, борьбе с изменениями климата, чему способствует включение в их деятельность нефинансовых экологических и социальных факторов, корпоративной социальной ответственности, ESG-критериев.

\section{Список литературы}

Бобылев, С.Н. (2019). Новые модели экономики и индикаторы устойчивого развития // Экономическое возрождение России, 3(61), 23-29.

Демчук, А.Л. (2020). Политические аспекты управления международными экологическими конфликтами // Вестник Томского государственного университета. Философия. Социология. Политология, 55, 240-248.

Мылина, М.М. (2014). Теоретико-методологические основы исследования экологических конфликтов как социальной категории // Историческая и социально-образовательная мысль, 6 (6), Ч. 2, 258-261.

Сабадаш, В. (2010). Ресурсная политика и экономика природопользования: теория и методология экологических конфликтов. Экологические конфликты в современной системе природопользования, под ред. Бобылева С.Н. и Сабадаш В. В., Сумы, Университетская книга, 352 с.

Терешина, М.В. (2009). Эколого-экономические конфликты в контексте национальной безопасности // Национальные интересы: приоритеты и безопасность: научно-практический и теоретический журнал, 38, 40-47.

Ховавко, И.Ю. (2016). Экономический анализ экологических конфликтов в Российской Федерации // Общество и экономика, $8,68-85$.

\section{References}

Barry, B., (1999). Sustainability and Intergenerational Justice. In Andrew Dobson (ed.), Fairness and Futurity, New York: Oxford University Press, 93-117.

Bobylev, S.N. (2019). Novye modeli jekonomiki i indikatory ustojchivogo razvitija. [New economic models and indicators of sustainable development]. In Jekonomicheskoe vozrozhdenie Rossii [Economic revival of Russia], 3(61), 23-29.

Demchuk, A.L. (2020) Politicheskie aspekty upravlenija mezhdunarodnymi jekologicheskimi konfliktami [Political Aspects of International Environmental Conflict]. In Vestnik Tomskogo gosudarstvennogo universiteta. Filosofija. Sociologija. Politologija [Management Bulletin of Tomsk State University. Philosophy. Sociology. Political science], 55, 240-248.

European Commission. A European Green Deal (2019). Available at: https://ec.europa.eu/info/sites/ default/files/european-green-deal-communication_en.pdf (accessed 15 May 2021). 
Homer Dixon, T.F., (1994). Environmental Scarcities and Violent Conflict. In International Security, 19(1), 5-40.

Internationalinvestment.net. UBS cuts funding for new Arctic offshore oil projects (2020). Available at: https://www.internationalinvestment.net/news/4012779/ubs-cuts-funding-arctic-offshore-oil-projects (accessed 15 May 2021).

Khovavko, I. Yu. (2016). Jekonomicheskij analiz jekologicheskih konfliktov v Rossijskoj Federacii [Economic analysis of environmental conflicts in the Russian Federation]. In Obshhestvo i jekonomika [Society and economy], 8, 68-85.

Le Billon, P. (2012). Wars of Plunder: Conflicts, Profits and the Politics of Resources. New York: Columbia University Press, $363 \mathrm{p}$.

Libiszewski, St. (1992). What is an Environmental Conflict? In CSS Environment and Conflicts Project Center for Security Studies (CSS). 15 p. Available at: https://www.files.ethz.ch/isn/236/doc_238_290_en.pdf

Martinez-Alier, J., Kallis, G., Veuthey, S., Walter, M., Temper, L. (2010). «Social metabolism, ecological distribution conflicts, and valuation languages». In Ecological Economics, 70(2), 153-158. Available at: https://doi.org/10.1016/j.ecolecon.2010.09.024

Martinez-Alier, J. (2004). Ecological Distribution Conflicts and Indicators of Sustainability. In International Journal of Political Economy, 34(1), 13-30.

Martinez-Alier, J. (2007). Identity and Power in Ecological Conflicts. In International Journal of Transdisiplinary Research, 2(1), 17-41.

Mason, S., Spillmann, K. (2005). Environmental Conflicts and Regional Conflict Management. In Welfare Economics and Sustainable Development, 2, 1-11. Available at: https://www.eolss.net/SampleChapters/C13/E1-21-04-05.pdf

Mylina, M.M. (2014) Teoretiko-metodologicheskie osnovy issledovanija jekologicheskih konfliktov kak social'noj kategorii [Theoretical and methodological foundations for the study of environmental conflicts as a social category]. In Istoricheskaja i social'no-obrazovatel'naja mysl' [Historical and socioeducational thought], 6(2, 2), 258-261.

Sabadash, V. (2010). Resursnaja politika i jekonomika prirodopol'zovanija: teorija i metodologija jekologicheskih konfliktov. Jekologicheskie konflikty v sovremennoj sisteme prirodopol'zovanija, pod red. Bobyleva S. N. i Sabadash V.V., Sumy, Universitetskaja kniga [Resource policy and economics of environmental management: theory and methodology of environmental conflicts. Environmental conflicts in the modern system of environmental management, ed. Bobylev S.N. and V.V. Sabadash, Sumy, University Book], $352 \mathrm{p}$.

Scheidel, A., Del Bene, D., Liu, J., Navas, G., Mingorría, S., Demaria, F., Avila, S., Roy, B., Ertör, I., Temper, L., Martínez-Alier, J. (2020). Environmental conflicts and defenders: A global overview. In Global Environmental Change, 63, 102-104.

Shlomi, Dinar (2011). Beyond Resource Wars. Scarccity Environmental Degradation and International Cooperation. Edited by Shlomi Dinar. The MIT Press, Cambrige, Massachusetts, London, England, $338 \mathrm{p}$.

Sustainable banking and our climate change strategy. Available at: https://personal.rbs.co.uk/personal/banking-with-royal-bank-of-scotland/sustainable-banking.html (accessed 15 May 2021).

Tereshina, M.V. (2009). Jekologo-jekonomicheskie konflikty v kontekste nacional'noj bezopasnosti [Environmental and economic conflicts in the context of national security]. In Nacional'nye interesy: prioritety i bezopasnost': nauchno-prakticheskij i teoreticheskij zhurnal [National interests: priorities and security: scientific-practical and theoretical journal], 38, 40-47.

The World Business Council for Sustainable Development. Guide to Corporate Ecosystem Valuation (2011). Available at: https://www.wbcsd.org/Programs/Redefining-Value/Business-Decision-Making/ Assess-and-Manage-Performance/Resources/Guide-to-Corporate-Ecosystem-Valuation (accessed 15 May 2021).

UN. Paris Agreement on climate change (2015). Available at: https://www.un.org/sustainabledevelopment/climate-action/ (accessed 15 May 2021). 
UN. General Assembly. The future we want (A/RES/66/288) (2012). Available at: https://www.un.org/ en/development/desa/population/migration/generalassembly/docs/globalcompact/A_RES_66_288.pdf (accessed 15 May 2021).

UN. General Assembly. Transforming our world: The 2030 agenda for sustainable development (A/ RES/70/1) (2015). Available at: https://www.un.org/en/development/desa/population/migration/generalassembly/docs/globalcompact/A_RES_70_1_E.pdf (accessed 15 May 2021).

UN Principles for Responcible Investment. Annual Report 2020 (2020). Available at: https://www. unpri.org/pri/about-the-pri/annual-report (accessed 15 May 2021).

World Bank Group. Russia Green Finance: Unlocking Opportunities for Green Investments (2018). Available at: https://www.worldbank.org/en/country/russia/publication/russia-unlocking-opportunities-forgreen-investments (accessed 15 May 2021).

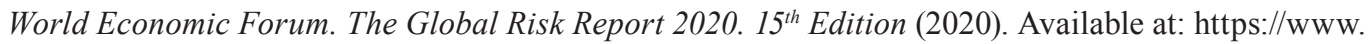
weforum.org/reports/the-global-risks-report-2020 (accessed 15 May 2021).

World Economic Forum. The Global Risk Report 2021. $16^{\text {th }}$ Edition (2021). Available at: https://www. weforum.org/reports/the-global-risks-report-2021 (accessed 15 May 2021). 